Xiao, J., Tait, M. and Kang, J. (2020) Understanding smellscapes: sense-making of smell-triggered emotions in place. Emotion, Space and Society 37(2020) 100710. https://doi.org/10.1016/i.emospa.2020.100710

\title{
Understanding smellscapes: sense-making of smell-triggered emotions in place
}

\begin{abstract}
Smells can evoke strong emotions and convey social meanings associated with people and places. This study explored the perceptual process of smellscape perceptions through a case study in Sheffield Railway Station and Bus Interchange. Walk-along interviews were used to collect data on people's perceptions onsite. It aims to understand how people make sense of their emotions triggered by smells in real life context, in relation to the physical space and onsite environment as well as their subjectivities. Nine perceptual patterns emerged in participants' sense-makings of smellscapes: recognising or identifying, associating, locating, evaluating, anticipating, contextualising comparing, generalising and personalising. A perceptual process model has been constructive from the empirical data mapping the interrelationships between smells, spaces and emotions. The findings from this paper contributes to the theoretical understanding of 'perception' in the smellscape concept. The perceptual process model provides a framework to interpret and communicate smellscapes in future design and planning practice.
\end{abstract}

\section{Introduction}

Supported by the growing literature on emotional geography (see Davidson, Bondi and Smith, 2005; Smith, Davidson, Cameron and Bondi, 2009), the attention of policy and social research has been drawn to the felt qualities of public spaces. Managing emotions and taking an emphatic approach are popularised in debates of public policies (Pykett, Jupp and Fiona, 2017). Historically, emotions have been considered gendered and personal and, as such, are excluded from the public agenda. However, Anderson and Smith (2001) have argued that people live through emotions and feelings, which cannot be gained through the visual and linguistic domains alone. The emotional reactions in place mediate the social relations between people and space, projecting how they live and respond to the surrounding environment (Davidson and Milligan, 2004). Emotional experiences and emotional behaviours, from both positive and negative perspectives, are increasingly the subject of research that informs new approaches to manage spaces and to create more meaningful places (see Barclay, 2020; Liddicoat, 2019). The bodily dimensions of emotions - sensorial experiences - are essential to the understand how we feel of ourselves in the space (Trnka, 2012). Osborne and Jones (2017) have experimented emotional-spatial explorations through a combined approach with three lenses- physiological (through biosensing data), environmental (through video/GPS data) and interpretive (through interviews). Other sensory cues, like sound, have increasingly drawn attention to individuals' emotions through environmental research and art practices (see Logan, 2016; Hemsworth, 2016). However, very few scholars have investigated the smell-emotional relations, in such empirical explorations of space. 
Xiao, J., Tait, M. and Kang, J. (2020) Understanding smellscapes: sense-making of smell-triggered emotions in place. Emotion, Space and Society 37(2020) 100710. https://doi.org/10.1016/i.emospa.2020.100710

Although smells are invisible and temporary, smellscapes are spatially structured from materials that construct the space. As Zardini and Schivelbusch (2005, p.276) have described

'...smells that are now universal and specific smells, produced by particular activities, sources of energy, aromas and spices, plants, flowers, animals and garbage overlay one another, forming landscapes of smell that are invisible, but nonetheless present and real...'.

Smells brings distinct identities to places and can connect people emotionally to those places. Understanding how people make sense of smell-triggered emotions contributes to the current literature on sensory and emotional geographies.

The smellscape considers how the perceived smell-environment of a particular place, at a particular time, responds to an individual's context and background (Authors, 2018). The smellscape concept itself is a construct of the relationship between human experiences of smells, the physical space and the context of place. Perception is at the core of the smellscape concept; Henshaw (2013) has referenced perception to sensation and cognition, emphasising the mental process of thinking. The perceiving process to detect and classify smells are different from the process to acknowledge individual's smell preferences (Herz, 2006, p.193). However, it is not clear that how the two processes work and whether emotions play role in these processes.

The central concern of this paper is how people make sense of their smell related emotional experiences in places as part of a perceptual process. Emotions triggered by smell experiences in places reflect individuals' evaluations of both their living environment and their existence within society. To begin with, we review scholarship on the role of smells in mediating individuals' emotions and perceptions of physical space and society. This review is followed by our case study of Sheffield Railway Station and Bus Interchange, in which we used walk-along interviews. The results are presented in three parts including, the emotions drawn out from participants' descriptions, the perceptual patterns participants use to make sense of their experiences, and, the perceptual process revealed from the empirical data. In light of our findings, we discuss the implications of the findings on how to communicate and interpret smellscapes within the debate of representational and non-representational space.

\section{Smells, emotions and places}

Tuan (1977) has argued that emotions are at the centre of all human experiences and give deep meanings to places. Looking further into the spatial emotional relations, Davidson and Milligan (2004) have also suggested that emotions are understandable and sensible in spatial structures, through different senses, at different scales and by responding to different contexts. The emotional reactions caused by our sensory experiences not only interpret environmental impacts on our daily routines, but also reflect people's perceptions of the city and its physical environment (Zardini and Schivelbusch, 2005). Referring to Lefebvre (1991), an individual's understanding of spaces, including cities, is constructed through the movements of their sensorial body and their mental reactions. Sensory stimuli, such as sounds, smells and colours, are essential to bring about emotional reactions in places (Mehrabian and Russell, 1974). 
Xiao, J., Tait, M. and Kang, J. (2020) Understanding smellscapes: sense-making of smell-triggered emotions in place. Emotion, Space and Society 37(2020) 100710. https://doi.org/10.1016/i.emospa.2020.100710

Smells, in Low's work (2005), were suggested as social medium employed to engender understanding and reading of social others in everyday life. However, smells in this paper are positioned in the centre of the triangular interrelationship between places, emotions and the society. We think, that they are a spatial-emotional medium or intermediary that interlinks and make smell triggered emotions make sense in relation to the physical and social structure of place in everyday living (Figure 1).

Physical space, smell sources, context, environment

\section{Place}

\section{Emotion}

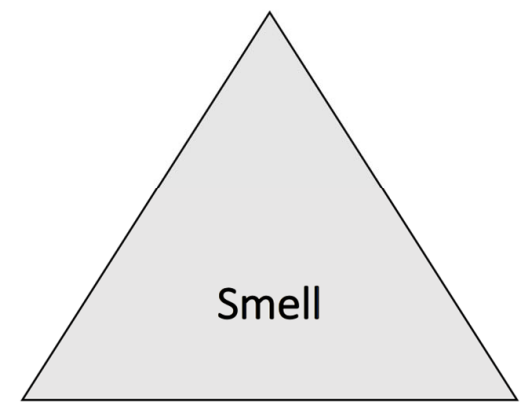

Memories, preferences, meanings

\section{Society}

Politics, communities, classes, gender

Figure 1 Smell as a spatial-emotional intermediary that links society, emotions and place Source: authors' own

Smells play in an important role in triggering emotions in places. Rodaway (1994, p.73) has noted, 'olfaction gives us not just a sensuous geography of places and spatial relationships, but also an emotional one of love and hate, pain and joy, attachment and alienation'. The sense of smell is emotional, arousing and cognitive (Porteous, 1985); and the recollective feature of smell experiences triggers 'emotional attachments and associations' (Henshaw,2013, p.31). Classen et al. (1994, p.2) have written that, 'a scent associated with a good experience can bring a rush of joy. A foul odour or once associated with a bad memory may make us grimace with disgust'. The action of smelling or sensing smells links the past and present, internal and outside world. As Hvastja and Zanuttini (1991, p.883) have also suggested, 'the main function of olfaction is not to recall odours for cognitive reasons but to respond to the odours encountered'.

The positive effects of aromas on mediating moods and relaxation have also been observed in clinical practice of aromatherapy (Buckle, 2014; Diego et al., 1998). In marketing research, scented products and shopping environments are found to enhance people's buying behaviours and their evaluation of a service (Spangenberg et al., 1996); smells are essential in creating pleasant retail atmospheres (Grewal et al., 2014). In line with such findings, Henshaw et al. (2016) have suggested that cities and their smells can be strategically planned and managed to provide explicit communications of a city's culture and identity. Positive smellscapes can bring restorative effects to cities, making inhabitants feel healthier and happier (Henshaw, 2013). Conversely, the negative impacts of sewage, traffic and tobacco smells can also significantly decrease people's experiences in such spaces. These positive and 
Xiao, J., Tait, M. and Kang, J. (2020) Understanding smellscapes: sense-making of smell-triggered emotions in place. Emotion, Space and Society 37(2020) 100710. https://doi.org/10.1016/i.emospa.2020.100710

negative experiences are important cues of emotional embodiment of individuals.

Odourless public spaces are iconic in western modern urban planning and city management practice - clean, impersonal and ordered. There are debates around public scenting, yet these do not include the ethics of using smells in the commercial discourse see Damian and Damian, 2006; Henshaw, 2013). The power of smells, and their relation to place perceptions has been undervalued and neglected (Classen et al., 1994). Scenting has been widely used as a strategy in marketing and tourism to attract customers, stimulate consumer behaviours and send out branding messages (Berry et al., 2006). For example, in 2012, the food company McCain implemented an interactive advertisement at bus stops in British cities in the cold month of February, targeting potential buyers with the smell of freshly baked potatoes (JCDecaux, 2012). Notably, such decisions, of where commercial smells are released in public spaces, are excluded from the dialogue of humanity and equal rights in cities. In a study of smoking in public spaces in Singapore, physical and social segregations were found between smokers and non-smokers caused by the perceived nuisance of cigarette smoke (Tan, 2012). As Śliwa and Riach (2012) have suggested, noticing different smells triggers a sense-making justification about one's own social status as well as others'. The historical view of perfumes used by women 'for the pleasure and enticement of men', also projects a discrimination on the enjoyment of smells and gender division (Classen et al., 1994, p.189); this view is somehow still true in the messages conveyed in most current perfume advertisements - with sexually appealing women as the main figures.

The emotional reactions towards smells in particular places are often aroused from the recalled memories of a particular moment in the past when people experienced a certain smell. Engen and Engen (1997, p.126) have suggested that 'the feeling about an odour becomes attached to a certain stimulus or situation'. Odour-evoked memories and imagination play an important role in smell-initiated emotional reactions. Also, Engen and Rose (1973) have compared the decline of memory accuracy between visual and olfactory senses with a group of students in a laboratory experiment. Their results showed that the degree of visual memory accuracy faded to zero after a few weeks, whilst the degree of olfactory memory accuracy stayed the same, at twenty percent of the first day, even one year later. The durable nature of odour memories has more potential to initiate a process of memory retrieval on perceiving a smell; odour-evoked memories also contribute to the hedonic properties of experiences and are found to be more emotionally potent (Herz and Engen, 1996). The emotion-memory bond in smell experiences are critical to one's perceptions of themselves and the environment.

\section{Case study: Smell-walking in Sheffield Railway Station and Bus Interchange}

To understand how people make sense of their smell experiences in everyday contexts, this research took an inductive qualitative inquiry. Grounded theory (Glaser and Strauss, 2009) provided a method to explore smellscapes systematically and to formulate a hypothesis to explain how people make sense of their smell experiences and the perceptual process of smellscapes. As such this research remained open to emerging patterns from the data (Authors, 2018) and was not limited to the existing discourse about 'individual and group dynamics of smell in the presentation of self and social interaction, constructed olfactory 
Xiao, J., Tait, M. and Kang, J. (2020) Understanding smellscapes: sense-making of smell-triggered emotions in place. Emotion, Space and Society 37(2020) 100710. https://doi.org/10.1016/i.emospa.2020.100710

configurations of social others based on gender and race' (Low, 2005, p.409). People's natural language descriptions were taken as an interpretation of feelings and emotions, and their descriptions as evidence to understand how they made sense of their feelings and emotions generated and associated them with smells, personal background and places.

To conduct detailed investigations on the relationships between people's experiences, the smell-environment, the physical space and the context, this research's case study was conducted at the Sheffield Railway Station and Bus Interchange, between July 2014 and February 2015. As a 'node' and 'place' (Bertolini, 2006), public transit spaces provide a rich everyday social and physical context in which to explore the complexity of smellscapes; their inclusive and neutral identity also provides a purposeless smell-environment in which to explore people's perceptions of smellscapes.

Smell-walking was used as a primary method to collect data about people's in-situ experiences of smells in the studied case. Smell-walking is a form of sensory walk where the researcher walks with individuals or groups to explore the smells that people detect and their perceptions of smells in the environment via conversations along a guided or designed route (Henshaw, 2013). McLean (2012) has found that smell-walks can evoke individuals' memories, emotions, and stories of places. A guided walk was designed to navigate participants through the case study site to encounter various functions and spatial forms (Figure 2). Walking as a transport means is practiced as part of everyday life as well as a social-technical assemblage exploring the social and physical environment at the same plane (Middleton, 2010). Sensory walks have been frequently used in empirical studies of sensory experiences in the urban environment (Degen and Rose, 2012). 
Xiao, J., Tait, M. and Kang, J. (2020) Understanding smellscapes: sense-making of smell-triggered emotions in place. Emotion, Space and Society 37(2020) 100710. https://doi.org/10.1016/i.emospa.2020.100710

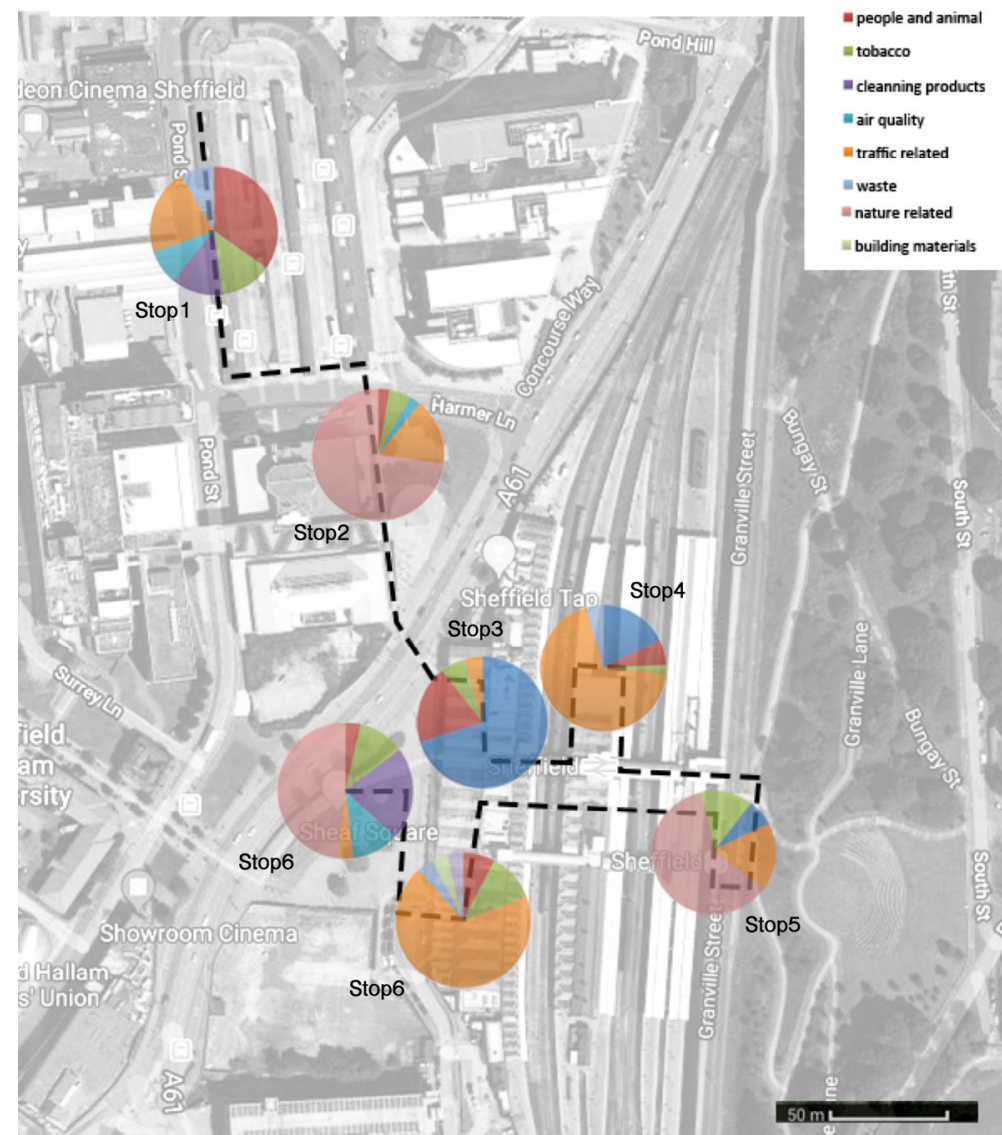

Figure 2. Route of the smell walking through the case study site in Sheffield with proportions of different smells detected along the route. The stops are: 1 , Bus Interchange Stand A; 2 , Station Pathway Greenery; 3, Railway Station Concourse; 4, Railway Station Platform; 5, Railway Station Tram Stop7, Sheaf Square; 6, Railway Station Taxi Rank; 7, Sheaf Square. Source: authors' own

Interview questions were asked as the walk progressed along each stop and inquired about the smells people detected and their experiences of smells in the environment. Nineteen participants (English speaking resident in the UK, aged between twenty-two and fifty-seven, including nine females and ten males) with a good sense of smell are interviewed for an average of 45 minutes. The ethics approval has been gained through the Research Ethics Committee from the Social Science Faculty at University of Sheffield. Participants were approached randomly onsite at the beginning of the data collection process, and then through a snowballing strategy. Data analysis was conducted along with the data collection process to help identify where additional participant information was required. This sampling process is 'a strategy to narrow the focus on emerging categories and a technique to develop and define them' (Charmaz, 2006, p.107). Consent was gained from all participants prior to the walk, agreeing that the data collected would be used for academic research and publications.

Each interview was recorded through a handheld voice recorder. Interview recordings were transcribed and analysed after each smell-walk to allow initial themes to emerge and to provide a guide for the follow-up sample recruitment. The transcribed interviews were analysed through line-by-line coding to capture detailed information and the meanings of words given by participants. Memo writing was used to categorise, reflect and synthesise information to derive meaningful themes from the data. Such a coding and memo-writing 
Xiao, J., Tait, M. and Kang, J. (2020) Understanding smellscapes: sense-making of smell-triggered emotions in place. Emotion, Space and Society 37(2020) 100710. https://doi.org/10.1016/i.emospa.2020.100710

process is an iterative process until the themes are consolidated with new theoretical concepts and frameworks (see Authors, 2018).

\section{Results}

Multimodality of emotions aroused by smells

Language descriptions of experiences in specific places indicated people's perceptions of their physical environmental settings (Bradley and Lang, 2000). In particular, modifiers in such descriptions often can be used to measure individuals' emotions, feelings and evaluations of the environment. As Classen et al. (1994, p.3) have argued, smell is 'a highly elusive phenomenon' and cannot be documented or named in western languages; however, we express our olfactory experiences through 'means of metaphors'. Narratives have the power to connect people and place; language delivers information about people's emotional experiences describing how they think and feel (Tuan, 1991). A cluster of modifiers associated with smell-related feelings and evaluations emerged from the conversations during the smellwalks (Table 1).

Table 1. Modifiers participants used to describe their feelings and evaluations of smellscapes in the case study. Source: authors' own

\begin{tabular}{|l|l|l|l|}
\hline Modifier & Frequency (n.) & Modifier & Frequency (n.) \\
\hline Happy & 2 & Strange & 1 \\
Familiar & 3 & Pleasing & 1 \\
Relaxing & 5 & Bothered & 3 \\
Annoying & 5 & Free & 1 \\
Good & 1 & Negative & 2 \\
Calming & 2 & Unhealthy & 3 \\
Soothing & 2 & Artificial & 1 \\
Pleasant & Normal & 3 \\
Unpleasant & Clean & 3 \\
Appropriate & 4 & Fresh & 6 \\
Inappropriate & 2 & Stale & 2 \\
Nice & 1 & Neutral & 1 \\
\hline
\end{tabular}

These modifiers, taken directly from participants' own verbal descriptions, have shown more qualities than the three dimensions - evaluation, potency and activity - suggested by Dalton et al. (2008). They also respond to the physical settings of space, personal factors and other sensory stimuli. For example, 'clean' as a feeling is different to 'good', indicating specific physical features of the environment such as good air quality, clean floors. 'Good' as a feeling has more focus on personal preference and physiological status. In many cases, modifiers of emotions and feelings were used in participants' descriptions, interweaved with perceptions of other sensory stimuli. For example:

'A bit watery smell and less fumes. I can smell the chlorine in the water. Nice, good. It makes me feel clean and reminds me of the smell of the swimming pool. It is a nice chemical smell... It makes me feel happy. I love water features. Actually, I like the sound of running water. It makes me feel free. Well, the smell of course plays a part of it' (Interview with participant S05, 10 July 2014) 
Xiao, J., Tait, M. and Kang, J. (2020) Understanding smellscapes: sense-making of smell-triggered emotions in place. Emotion, Space and Society 37(2020) 100710. https://doi.org/10.1016/i.emospa.2020.100710

Here, the interaction of auditory experiences of the water was emphasised in a conversation about smellscapes. The feeling of 'happy' and 'free' wasan emotional reaction across perceived sounds and smells in the scenario. Modifiers given by participants in such cases were also affected by the multimodality of language and emotions. In fact, both the language and sensory-motor systems share the same structure in the human brain, with the result that language descriptions and sensory experiences are interrelated (Gallese and Lakoff, 2005).

Through semantic analysis of 50 pairs of binary descriptors - based on the non-olfactory stimuli developed by Osgood (1962) - Dalton et al. (2008) found nine pairs of binary descriptors that people most frequently associate with smells: fresh-stale, good-bad, happysad, harmonious-inharmonious, healthy-unhealthy, beautiful-ugly, smooth-rough, clean-dirty and safe-dangerous. However, these laboratory results have not been examined in empirical studies to show whether they match people's natural descriptions of smells and smellassociated emotions and feelings in places. From our results, shown in Table 1, the most frequently naturally used modifiers in the studied case were: happy, familiar, annoying, relaxing, pleasant, unpleasant, bothered, fresh, normal, clean - they are not necessarily binary pairs. Given the limitation of sample scale, the frequencies are only used here to see which emotional responses were dominant in the studied context, whilst not attempting to produce generalisations of smell descriptors.

\section{Perceptual patterns in sense-making smell-aroused emotions}

People have habits of sensing and these are often reflected in their ways of identifying and describing sensory experiences (Cain et al., 1998). Patterns emerged from this case study that reflected people's habits of sensing smells in relation to space, objects and people (Figure 3 ). 
Xiao, J., Tait, M. and Kang, J. (2020) Understanding smellscapes: sense-making of smell-triggered emotions in place. Emotion, Space and Society 37(2020) 100710. https://doi.org/10.1016/i.emospa.2020.100710

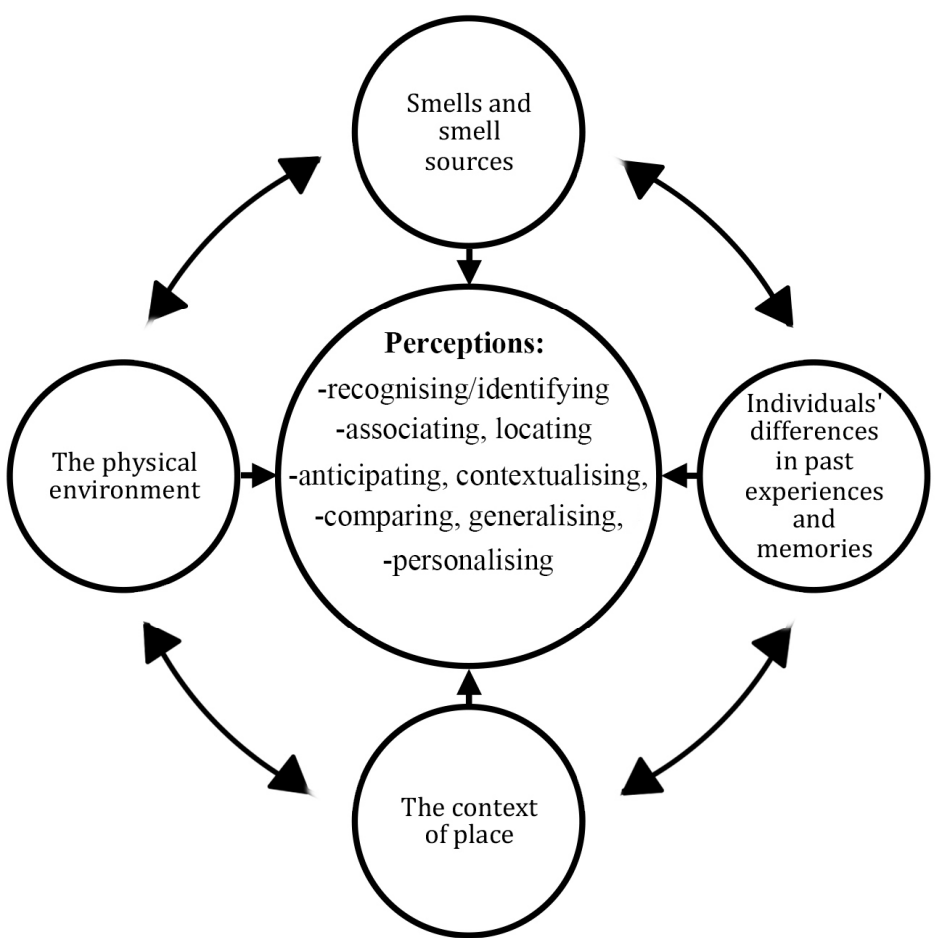

Figure 3. Emerging patterns of sense-making from the analysis of interviews with participants during smell-walks. Source: authors' own

On detecting a smell, participants often recognised whether they had encountered it before, or not. Familiarity had a significant impact on people's abilities to recognise smells (Cain et al., 1991; Ayabe-Kanamura et al., 1998). Waskul and Vannini (2008) have suggested that people's immediate interpretations of smells are often related to smell sources and their connotative meanings. However, in many cases, participants could not identify or use accurate descriptions to define smells or smell-sources. For example, when been asked what smells they detected in the bus interchange, one participant described the smell as an 'old smell':

'It has an old smell. How can I explain this ... You know modern buildings? They always associate with the clean smell. But, here, it has a bit dusty smell. It not that dusty, but, for now, it is kind of humid and dusty feeling' (Interview with Participant S09, 22 July 2014).

In this case, the concept of smell started with an abstract form and then moved on to a specific idea. This process involved recognising action in their response but without accuracy. Laboratory experiments have identified that most people find it much more difficult to identify exactly what the smells are without visual aids (words or images) in a decontextualised condition (Cain et al., 1991). This echoes Rose's (2001) longstanding perspective about multimodality in visual perceptions. In this research, the method participants used to recognise or identify smells was noted either by association with everyday experiences and memories, or by visual references to objects and people's behaviours that stimulated the experience imaginary. For example, many participants associated traffic fumes with poor air quality and crowded environments, which had negative impacts on their overall perceptions. Herz (2006) has argued that people's knowledge of 
Xiao, J., Tait, M. and Kang, J. (2020) Understanding smellscapes: sense-making of smell-triggered emotions in place. Emotion, Space and Society 37(2020) 100710. https://doi.org/10.1016/i.emospa.2020.100710

smells is learnt through day-to-day experiences and practice whether positive or negative and these powerful in forming preconceptions.

When detecting a smell, participants often attempted to correlate between the smells and the physical environment, while also orientating themselves to trace the sources of the smells detected. For example:

'Now we are in the concourse, I smelt someone's perfume in front of us. I can smell cigarette [smoke] from the door where people are smoking by the door. Uh, I can also smell some food here from the pasty shop and a little bit smell of coffee from the café in the middle. But it is not overpowering' (Interview with Participant S09, 22 July 2014).

The perceiver-centred notion was identical when participants located themselves in relation to distances and orientations of smell-sources in the environment to justify their recognition or identification of smells. This result echoes Marr's (1982) suggestion that people always locate themselves in relation to objects in places. However, the action of locating was based on direct observations of the surrounding environment onsite, without connotative interpretation.

Herz (2006) has suggested that people know immediately upon detecting a smell whether they like it or not, and this pleasure or pain experience determines their interpretation and evaluation of the associated objects, people and places as good or bad. Evaluating smellscapes is a rationalising process where people use logic to explain their personal feelings and evaluations, taking into account factors such as appropriate, dislike and unfamiliar. An analytical process is always involved in evaluations, drawing references from one's expectations and preconceptions of smells and places. For example:

'It is just the train smells over the platform. I thought I will be able to smell the coffee, but I can't at all. It is just the trains. Quite strong smell' (Interview with participant S05, 10 July 2014).

The preconceptions of objects and physical settings of a place are often the initiatives for anticipating smellscapes. The anticipation of smellscapes sets out a standard of an acceptable smell-environment for those perceiving it; their justifications are based on the familiarity of similar physical environments, smells and smell-sources. When the actual smellscape differs from what they anticipated, people notice the difference immediately and make a response. For example, when detecting the smell of chlorine from the water feature in front of the station, a participant said:

'I don't expect chlorine, it usually associates with swimming pool, it is an indoor environment, obviously, outside tends to be more natural water smell. It is now I can smell chlorine, I don't expect that, I'd wish to smell more natural water, maybe not sea water, but just not artificial smell.' (Interview with participant S07, 11 July 2014) 
Xiao, J., Tait, M. and Kang, J. (2020) Understanding smellscapes: sense-making of smell-triggered emotions in place. Emotion, Space and Society 37(2020) 100710. https://doi.org/10.1016/i.emospa.2020.100710

Contextualising smells is a negotiated structure of context and detected smells (Waskul and Vannini, 2008). Context - which can be a set of background conditions or facts about the place or a particular event within it - plays a decisive role on the quality of smellscapes in a place (Authors, 2018). When contextualising, participants most valued the congruency of perceived smells within their contexts. For example, one participant commented on the smell of trains at the platform:

'Well, it is a train station, I expected to smell the smells of trains. So, it is not that unpleasant to me, because I know what it will smell like' (Interview with participant S17, 04 February 2015).

Comparing with a contrasting or similar smell experience provided perceivers with references for evaluating smellscapes. Fine (1995, p.256) has argued that people are likely to use their past experiences as basis for judgement and evaluation. Such comparisons are based on memories of a similar or contrasting experiences in similar contexts. Often, there will be a certain level of associations involved, however, comparisons may lead to an evaluation from a critical point of view. Participants also compared experiences along the route, these comparisons are more vivid and detailed. For example:

'I feel refreshed, more comfortable, because we were inside the bus station. It is an enclosed space that you don't smell fresh air in it. But here, it's more open area. I can easily sense the difference. It was too warm inside the bus station and there is no airflow. And you smell people inside it. But, outside there, I can feel the breeze. And it doesn't smell like people. I prefer the outdoor smell' (Interview with S04, 08 July 2014).

Participants sometimes tried to conclude and summarise smellscape features according to common experiences or ideologies shared by the public; such generalisations often influenced their expectations and acceptance of smellscapes. For example:

'Obviously, with the clean smells, you associate with clean things. I think it is just everybody likes clean things. If you cleaned your room, it would be a fresh smell and quite nice' (Interview with participant S07, 11 July 2014).

In this example, the participant generalised two things based on her own observations: a clean smell was associated with clean things, and everyone likes clean smells. Such generalised rules might be true to people from the same social and cultural backgrounds, yet they are not objective enough to apply in other contexts.

When evaluating smellscapes, participants often drew upon their personal preferences and habits. Smell preferences and habituations are essential to smellscape perceptions (Henshaw, 2013) and personalised smellscapes may produce emotional responses, expressed in terms like 'familiar', 'homely' and 'annoying'. When personalising a smellscape, participants were often aware that they gave personal opinions that might not be like those of other people. Śliwa and Riach (2012) have considered smell as a process of 'othering' to differentiate and associate. Past experiences and memories are often the source of smell-information to which people can refer (Schiffman, 1990), and given that odour memories are long-lasting, people are likely to experience personalising, recalling happy or unhappy memories of themselves. 
Xiao, J., Tait, M. and Kang, J. (2020) Understanding smellscapes: sense-making of smell-triggered emotions in place. Emotion, Space and Society 37(2020) 100710. https://doi.org/10.1016/i.emospa.2020.100710

Personalising makes one's perception of the smell-environment unique with personal meanings. As Synnott (1993, p.187) has argued, smells are integrated with people's personal lives, imbued with memories and meanings. For example:

'I don't mind the train smell because it reminds me of going away. I don't use trains for business or work. Mine would be for pleasure. All I remember is pleasurable journeys. So, I quite like the smell of the train, it is not something that I experience everyday either, for me, I'd be going for a trip on a train, which is a pleasurable experience anyway, so, I don't mind smelling the train' (Interview with participant S17, 04 February 2015) .

All these perceptual patterns contributed to the sense-making of emotions aroused by the smells in places and work differently in different situations in combination. The smellscape components - the context of place, individuals' backgrounds, the smell-environment, and the physical space - worked at different levels, responding to different situations. For example, in the case above, attention was given to the individual's background, associating a personalised meaning to the grassy smell suggestive of a park and home. Such perceptual patterns showed the momentary interrelationships between the four smellscape components.

\section{Attention-driven perceptual process}

In the interview, participants conducted a process: from acquiring knowledge of the smellenvironment, understanding the perceived smell-environment, and interpreting the overall experience to the interviewer specific to the interview questions. Although this followed theoretical assumptions, the interview questions were open-ended, which left space to understand the actual process of perceiving smellscapes. Figure 4 shows a perceptual process constructed from the participants' descriptions. 
Xiao, J., Tait, M. and Kang, J. (2020) Understanding smellscapes: sense-making of smell-triggered emotions in place. Emotion, Space and Society 37(2020) 100710. https://doi.org/10.1016/i.emospa.2020.100710

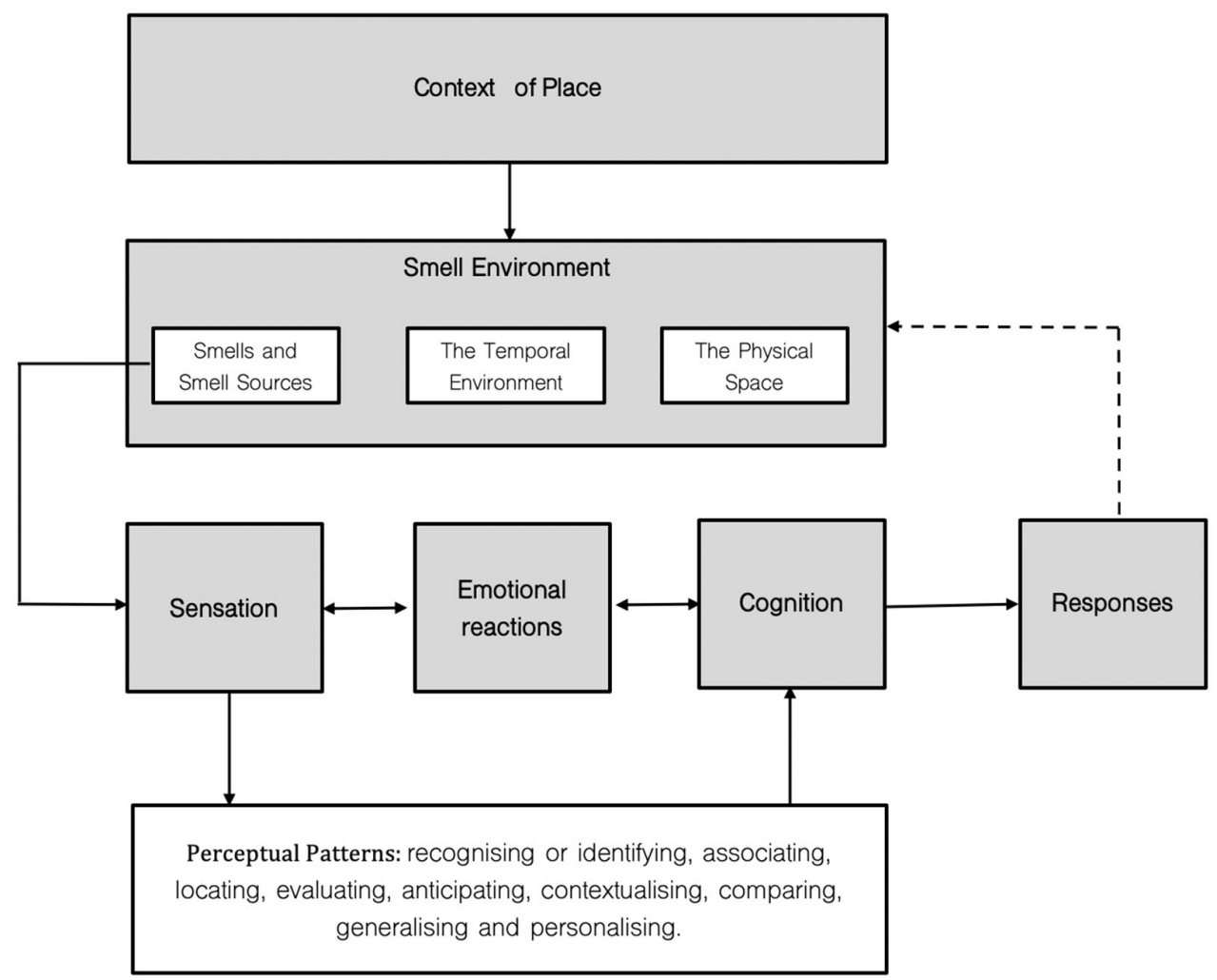

Figure 4. Perceptual process of smellscapes constructed from participants' descriptions of their experiences during the smell-walks in the case study. Source: authors' own

The conscious detection of smells played an important role in the perceptual process to activate the cognitive process. When a smell caught an individual's attention, they immediately noticed the smell-environment and made an effort to recognise or identify the smell; possibly also proceeding to an evaluation of the smell-environment. However, there wass also an unconscious detection of smells that contributed to the overall perception. Jacquot et al. (2004, p.51) has defined this unconscious detection as 'an activation of the autonomic nervous system in response to an external stimulus without subjects' awareness of the present stimulus', including the detections from the trigeminal component of the nasal stimuli. Given the methods used in this study, it was hard to tell whether unconscious detections of smells occurred along the walks or not; however, the responses of 'not noticing' and 'ignoring' extracted from the conversations led to the question of paying attention to perceptual process.

In the inquiry, some participants' immediate responses to what the smells and sources were in the space were 'not really...' or 'I can smell...'. Generally, participants would not give a definite 'no', but they were more likely to say, 'not really' or 'nothing particular' instead. Most of the time, when saying such phrases, they were surrounded by 'background smells' of low intensities and are neutral to their preferences. For example:

'Nothing particular, there is nothing like or dislike of this space in my head. It is very neutral. I think the weather is also a contributing aspect to the smell-environment, 
Xiao, J., Tait, M. and Kang, J. (2020) Understanding smellscapes: sense-making of smell-triggered emotions in place. Emotion, Space and Society 37(2020) 100710. https://doi.org/10.1016/i.emospa.2020.100710

because if it is in summer, it is easier for you to detect more smells. But now, it is winter, it is just neutral' (Interview with participant S16, 16 January 2015).

This 'not noticing' response was also commonly found in smell-walks conducted by Henshaw (2013). Whether noticing or not noticing is based on the subjective evaluation of detection threshold of smells in the space, experiences of smells are not necessarily consciously directed by our attention (Hvastja and Zanuttini, 1991). The status of the body and mind in a situation mostly determines the level of attention given to smells in the environment; people may not notice smells when they are active, i.e. running and walking fast. It is likely that people have lower sensory detections during vigorous activity compared to passive movements (sitting and standing) -because their attention is diverted to bodily movement or the surrounding environment (Chapman, et al., 1987). For example, one participant commented:

'You know when I am walking, I don't really take notice of smells. I just take care about the surroundings, what I see, you know. So now, when you tell me to smell something, it's more different. I begin to take notice of smells' (Interview with participant S08, 21 July 2014).

Attention plays an important role in activating the cognitive process. Individuals' emotional relationships to places are dynamic processes of consciousness and unconsciousness to attach or detach themselves to the environment (Manzo, 2003). Debner and Jacoby (1994) have examined the role of attention in conscious and unconscious perceptions and confirmed that attention can activate the autonomy of mental processes to achieve a goal even without awareness. In this research, when asked to identify a smell, participants automatically activated the subconscious perceptions of the smell-environment. However, it is worth pointing out that sensation in this process is not a one-off; the repeated action of breathing along the walk has continued to enrich information about the smells in the space. As Riach and Warren (2015, p.795) have suggested, 'inhaling also involves a continual exchange and enmeshment of experience that challenges and confuses ideas of interiority and exteriority'. Breathing brings unconscious detection of smells, which produces a secondary layer of information of the smell-environment. The movement of the body also enables the changes of the microenvironment around the nose and the air taken in, responding to the distance and orientations to different smell sources.

The normalness and abnormal-ness are frequently mentioned in participants' responses, which indicated whether perceived smells in places are different from their expectations. For example:

'Not really, it is just a hot day, I can just smell a bit of cars. But it is really mixed with the hot weather and I feel it is normal. I can't really tell. It is nothing bad really. Yeah, nothing else' (Interview with participant S05, 10 July 2014).

In the example above, the participant explained detecting 'only a bit of cars' after saying 'not really (detecting any smells)'. The immediate response of 'not really' lies behind her familiarity with the smell of cars mixed with other environmental background odours in the hot weather. The conclusion the participant made of perceiving car fumes in the station being 
Xiao, J., Tait, M. and Kang, J. (2020) Understanding smellscapes: sense-making of smell-triggered emotions in place. Emotion, Space and Society 37(2020) 100710. https://doi.org/10.1016/i.emospa.2020.100710

normal is the reason for her not paying immediate attention to the smell environment at the beginning. This focus would bring up the ethical issue of taking a participant onsite to make them aware of the smell-environment and their subconscious reactions to it - in contrast, this 'a bit car smell' would probably not be noticed in her normal daily routine. People experience a process that involves adaptation, fatigue and habituation when encountering repeated smells (Naus, 1984; Schiffman, 1990), which may result in less sensitivity to such smells. In the case where people are exposed to background smells similar to their daily living environment, if there is no significant change in smells from one space to another, they will rarely pay attention to these background odours. Normalness is an intermediate form that can either lead to evaluation or end the perception at the initial stage; this normalcy will depend on the intensities of smells in the space and whether they catch the attention of the perceiver. This 'normalness' response was not dissimilar from Low's $(2005, \mathrm{p} .408)$ finding on 'the sense of normalcy' in everyday experiences of smells.

An 'ignoring' response occurred frequently when participants thought the perceived smellenvironment did not have a significant influence on what they were doing in the space. For example, the smell of diesel on platforms was frequently commented on as unpleasant by participants, whilst it would not stop them waiting for trains on the platform. Here, participants contextualised the smellscape for the transit environment and took into consideration the purpose of visit to decide their responses. As such, 'ignoring' is a way of controlling emotional reactions towards the smell-environment - when a decision is made to ignore, lower attention will be given to the smells in the space.

Existing research suggests that smells can cause different behavioural responses in the space, such as approaching and avoiding behaviours (Largey and Watson, 1972). These behavioural responses may lead to changes to the general context or the positions of perceivers in the environment. For example, empty or covered trash bins may result in a change of walking routes. However, in this investigation, behavioural responses were not purposely studied and considered in the research design. Participants did not behaviourally respond to smellscapes during interviews whilst their descriptions did indicate their potential behavioural responses. For example:

'It is very unpleasant. Every time when I smell it, I feel like I have to protect my lungs. Because it is something I believe is unhealthy for my respiration system' (Interview with participant S14, 05 December 2014).

The perceptual process revealed a process of reasoning and justification, with different levels of attention-giving and controlling. Although it is debatable whether unconscious detection of smells proceeded cognitive responses, attention in this empirical research activated the cognitive process. Thrift (2004, p.152) has argued that body practices in spaces shaped by emotions are an 'important part of the body's anticipation of the moment'. Emotions are conscious and expressible whilst feelings are not. In his discussions of 'real' experiences, the instantaneous experience in fact does not truly exist since there is a time structure applied to the bodily responses or processes of any sensory perceptions (Thrift, 2004, p.152). Preconscious awareness of objects, spaces and people produce anticipations, which are intuitional but may incite a conscious awareness that can be considered a means of focussing and sanctioning action. This preconscious awareness might come from habituations of 
Xiao, J., Tait, M. and Kang, J. (2020) Understanding smellscapes: sense-making of smell-triggered emotions in place. Emotion, Space and Society 37(2020) 100710. https://doi.org/10.1016/i.emospa.2020.100710

everyday living and the common sense. Thrift (2004, p.152) has also suggested 'emotion is corporeal rather than discursive reasoning'. In between sensations and cognitions, the aroused emotions and physiological responses mediated the iterative process. Responses, as contrast to the natural bodily involvement, were the result of discursive reasoning, like 'ignoring' found in the case study site. Purposeful responses to the smell-environment perceived might interfere with future expectations of such spaces or uses. Both intuitive and discursive reasoning are involved in the perceptual process, and responses to the smellenvironment depend on people's evaluations and purposes for using the space. However, either response stimulates an iterative process of perceiving the changing smell-environment through the movements of the human body.

\section{Reflections on findings}

Tolaas (2010, p.153) has argued that 'the study of urban smells provides an additional dimension to our understanding of cities, enriches our sensual experience and provides input for urban design and architecture to communicate and understand the invisible city'. Smells play important roles in the learning process of places (Henshaw, 2017). In the discussion of smellscapes here, smells are taken as an agency, as the physical space, to facilitate or activate the thought resident in the human body. The thought or perception is the medium to reconstruct the social-spatial relationships between smells, individuals and emotions. This reconstruction has led to discussion of the nature of smellscapes as non-representational and the paradoxical needs of representational interpretations.

Referring to Thrift (1996, p.4), nonrepresentational space emphasises the 'precedence over lived experiences and materiality', which is beyond the representational dimensions given by physical structure and order. The production of space is with the embodiment of human bodies through a dynamic process of interactions between tangible and intangible elements. Canniford and Riach (2018) have suggested that smell encodes spaces with meaning and power that link people and punctuate their movements within the space. The perceptual process revealed in the study wass not static - the interactions between the body, space and smells continuously formed 'new' thinking and actions. Although pre-consciousness of smells was not measured, the 'not noticing' and 'normalness' reactions were indications of habituations and preconceptions, which formed the pre-consciousness of smells. Henshaw et al. (2016) have suggested that incorporating unintentional and ambient smells synonymous with the contextual place can create unique place identities and emotional resonance. The perceptual process constructed from this research can help future explorations of smell to examine the conditions or smells that activate emotions, or not, as the case may be.

The intangibility and ephemerality of smells makes it difficult to represent and communicate in all design processes. Limitation on interpretations and describing smellscapes in English culture and language have been acknowledged in previous studies (Classen, et al., 1994; Majid and Burenhult, 2014). The subjective features and various factors also bring difficulties to understanding, characterising and interpreting smellscapes (Henshaw, 2017).

Contemporary urban and architectural practice still rely on representational tools and visual language to communicate and design spaces: it remains a challenge to design or plan for the non-representational qualities of spaces. Lefebvre's (1991) argument that spaces are socially 
Xiao, J., Tait, M. and Kang, J. (2020) Understanding smellscapes: sense-making of smell-triggered emotions in place. Emotion, Space and Society 37(2020) 100710. https://doi.org/10.1016/i.emospa.2020.100710

constructed through the triangular relationship between representational spaces, representations of space, and spatial practices over time holds resonance for our examination of smellscapes. Smellscapes are representations of individuals' imaginations of places, triggered by smells in a space-time structure. Spatial practices, through the body's movements within spaces, are constrained and shaped by the materiality of the space (meaning the physical forms, materials and design). The self-conceptualisation or sensemaking of smellscapes needs to be better understood by different stakeholders applying place-making with smell. The concept of self is important in perceptions of environment, and the interpretation of the environment is a special and meaningful process in relation to the sense of self. People choose environments that are congruent with their self-concept, modifying settings to better represent themselves, or moving to find places, which are more congruent with their sense of self (Twigger-Ross and Uzzell, 1996). Such perceptual patterns have mapped out the different 'rules' participants used to rationalise the emotional reactions and responses to the smellscape. These can be used to predict or reconstruct the socialemotional space associated with smells.

Visual cues are vital, in everyday contexts, concerning smell perception. As revealed in participants' descriptions, there was a multimodality (Rose, 2001) involved in smell-aroused emotional reactions. Ehrlichman and Bastone (1992) have examined the role of smells in arousing emotional reactions with and without visually present objects (smell sources) and have suggested that the ability of smells to arouse emotions decreased without visual cues. Visual information, without smell, might also recall odour-related memories (Engen and Rose, 1973). The congruency of smellscapes was often based on the visual perceptions of the environment and the expectations of smells inside the space. The emotional and imaginative feature of smells can empower spaces to set boundaries and engineer people's impressions of cities (Synnott, 1991). The perceptual process constructed from this paper can potentially give a framework for practitioners to link to representational and non-representational spaces. Smellwalks are essential tools to investigate the existing smellscapes. Verbal or diagrammatical information can be constructed referring to the perceptual process model addressing individual components. Curated smellwalks with purposeful scents and visual cues can be explored in the future as a way to evaluate and modify design schemes.

The theoretical contribution of this work is the perceptual process in smellscape based on empirical data, which takes in the impact of the physical space and the context of place. Herein, smell has been considered as a spatial-emotional intermediary, bridging interpersonal experiences of smells and the social-spatial structure of place. This smellscape perception model constructed provides new insights into understanding the smellscape concept and has practical contributions to the interpretation and communication of smellscapes at different stages in the spatial planning and design process.

Future research would empirically examine how the perceptual patterns and process model can be used to understand and interpret people's responses to the smellscape in certain contextual places. In particular, further investigative studies - from the perspectives of both the designers and the public - could be conducted on how to apply the process model to best communicate their ideas and experiences of smellscapes in a design process. In addition, more empirical work should be conducted through walkalong interviews in different contextual spaces to gather the emotional descriptions elicited by smells to build a vocabulary 
Xiao, J., Tait, M. and Kang, J. (2020) Understanding smellscapes: sense-making of smell-triggered emotions in place. Emotion, Space and Society 37(2020) 100710. https://doi.org/10.1016/i.emospa.2020.100710

library that can be used for future semantic analysis.

\section{References}

Anderson, K. and Smith, S.J., 2001. Emotional geographies. Transactions of The Institute of British geographers, 26(1), pp.7-10.

Authors, 2018. A perceptual model of smellscape pleasantness. Cities, 76, 105-115.

Ayabe-Kanamura, S., Schicker, I., Laska, M., Hudson, R., Distel, H., Kobayakawa, T. and Saito, S., 1998. Differences in perception of everyday odors: a Japanese-German crosscultural study. Chemical Senses, 23(1), 31-38.

Barclay, K., 2020. Family, memory and emotion in the museum. Emotion, Space and Society, 35, 100679.

Berry, L.L., Wall, E.A. and Carbone, L.P., 2006. Service clues and customer assessment of the service experience: Lessons from marketing. The Academy of Management Perspectives, 20(2), 43-57.

Bertolini, L., 2006. Fostering urbanity in a mobile society: linking concepts and practices. Journal of urban design, 11(3), 319-334.

Bradley, M.M. and Lang, P.J., 2000. Measuring emotion: Behavior, feeling, and physiology. Cognitive neuroscience of emotion, 25, 49-59.

Buckle, J., 2014. Clinical aromatherapy: essential oils in healthcare. Elsevier Health Sciences, Edinburgh.

Cain, W. S., de Wijk, R., Lulejian, C., Schiet, F. and See, L. C., 1998. Odor identification: perceptual and semantic dimensions. Chemical Senses, 23(3), 309-326.

Canniford, R., Riach, K. and Hill, T., 2018. Nosenography: How smell constitutes meaning, identity and temporal experience in spatial assemblages. Marketing Theory, 18(2), 234-248.

Charmaz, K., 2006. Constructing Grounded Theory: A Practical Guide Through Qualitative Analysis. Sage, London.

Chapman, C. E., Bushnell, M. C., Miron, D., Duncan, G. H. and Lund, J. P., 1987. Sensory perception during movement in man. Experimental Brain Research, 68(3), 516-524.

Classen, C., Howes, D. and Synnott, A., 1994. Aroma: The cultural history of smell. Taylor \& Francis, New York.

Dalton, P., Maute, C., Oshida, A., Hikichi, S. and Izumi, Y. U., 2008. The use of semantic differential scaling to define the multidimensional representation of odors. Journal of Sensory Studies, 23(4), 485-497. 
Xiao, J., Tait, M. and Kang, J. (2020) Understanding smellscapes: sense-making of smell-triggered emotions in place. Emotion, Space and Society 37(2020) 100710. https://doi.org/10.1016/i.emospa.2020.100710

Davidson, J., Bondi, L. and Smith, M., 2005. Emotional Geographies. Routledge, London.

Debner, J. A. and Jacoby, L. L., 1994. Unconscious perception: Attention, awareness, and control. Journal of Experimental Psychology: Learning, Memory, and Cognition, 20(2), 304.

Damian, P. and Damian, K., 2006. Environmental fragrancing. In Drobnick, J. (ed.) The Smell Culture Reader. Berg Publishers, Oxford, pp.148-160.

Davidson, J. and Milligan, C., 2004. Embodying emotion sensing space: introducing emotional geographies. Social \& Cutural Geography. 5(4), 523-532.

Degen, M.M. and Rose, G., 2012. The sensory experiencing of urban design: the role of walking and perceptual memory. Urban Studies, 49(15), 3271-3287.

Diego, M. A., Jones, N. A., Field, T., Hernandez-Reif, M., Schanberg, S., Kuhn, C., Galamaga, M., McAdam, V. and Galamaga, R., 1998. Aromatherapy positively affects mood, EEG patterns of alertness and math computations. International Journal of Neuroscience, 96(3-4), 217-224.

Ehrlichman, H. and Bastone, L., 1992. Olfaction and emotion. In Science of olfaction (pp. 410-438). New York: Springer.

Engen, T. and Ross, B. M., 1973. Long-term memory of odors with and without verbal descriptions. Journal of Experimental Psychology, 100(2), 221.

Engen, T., \& Engen, E. A. (1997). Relationship between development of odor perception and language. Enfance, 1, 125-140.

Fine, G. A., 1995. Wittgenstein's Kitchen: Sharing Meaning in Restaurant Work. Theory and Society, 24, 245-269.

Gallese, V. and Lakoff, G., 2005. The brain's concepts: The role of the sensory-motor system in conceptual knowledge. Cognitive neuropsychology,22(3-4), 455-479.

Glaser, B. G. and Strauss, A. L., 2009. The Discovery of Grounded Theory: Strategies for Qualitative Research. Transaction Publishers, New Jersey.

Grewal, D., Roggeveen, A. L., Puccinelli, N. M. and Spence, C., 2014. Retail atmospherics and in-store nonverbal cues: an introduction. Psychology \& Marketing, 31(7), 469-471.

Henshaw, V., 2013. Urban smellscapes: Understanding and designing city smell environments. Routledge, London.

Henshaw, V., Medway, D., Warnaby, G. and Perkins, C., 2016. Marketing the 'city of smells'. Marketing Theory, 16(2), 153-170. 
Xiao, J., Tait, M. and Kang, J. (2020) Understanding smellscapes: sense-making of smell-triggered emotions in place. Emotion, Space and Society 37(2020) 100710. https://doi.org/10.1016/i.emospa.2020.100710

Henshaw, V., 2017. Experiential learning and olfactory architectures: accommodating smells in teaching practices in built environment. In Henshaw, V., McLean, K., Medway, D., Perkins, C. and Warnaby, G. (eds.). Designing with smell: practices, techniques and challenges. Routledge, London, pp.160-168.

Hemsworth, K., 2016. 'Feeling the range': Emotional geographies of sound in prisons. Emotion, Space and Society, 20, 90-97.

Herz, R. S., 2006. I know what I like: Understanding odor preferences. In J. Drobnick (ed.). The smell culture reader. Berg Publishers, Oxford, pp. 190-203.

Herz, R.S. and Engen, T., 1996. Odor memory: review and analysis.Psychonomic Bulletin \& Review, 3(3), 300-313.

Hvastja, L. and Zanuttini, L., 1991. Recognition of nonexplicitly presented odors. Perceptual and Motor Skills, 72(3), 883-892.

Jacquot, L., Monnin, J. and Brand, G., 2004. Unconscious odor detection could not be due to odor itself. Brain Research, 1002(1-2), 51-54.

JCDecaux, 2012. McCain Targets The Senses: Cities, Creative Solutions. Accessed on $22^{\text {nd }}$ November 2019 at https://www.jcdecaux.co.uk/news/mccain-targets-senses

Koch, R. and Latham, A., 2014. Representing and imagining the city. Cities and Social Change: Encounters with Contemporary Urbanism. Sage, London, pp. 14-32.

Jupp, E., Pykett, J. and Smith, F.M, 2017. Introduction: Governing with feeling. In Jupp, E., Pykett, J. and Smith, F.M. eds., Emotional States: Sites and Spaces of Affective Governance. Taylor \& Francis, New York, pp. 1-18.

Koch, R. and Latham, A., 2014. Representing and imagining the city. Cities and Social Change: Encounters with Contemporary Urbanism. Sage, London, pp. 14-32.

Largey, G.P. and Watson, D.R. 1972. The sociology of odors. American Journal of Sociology, 77(6), 1021-1034.

Lefebvre, H., 1991. The production of space. Vol. 142. Translated by Nicholson-Smith, D., Blackwell, Oxford.

Liddicoat, S., 2019. Affective spectrality in therapeutic space. Emotion, Space and Society, 32, 100588.

Logan, K., 2016. The word has turn. Emotion, Space and Society, 20, 120-123.

Low, K. E., 2005. Ruminations on smell as a sociocultural phenomenon. Current Sociology, 53(3), 397-417. 
Xiao, J., Tait, M. and Kang, J. (2020) Understanding smellscapes: sense-making of smell-triggered emotions in place. Emotion, Space and Society 37(2020) 100710. https://doi.org/10.1016/i.emospa.2020.100710

Manzo, L.C., 2003. Beyond house and haven: Toward a revisioning of emotional relationships with places. Journal of environmental psychology,23(1), 47-61.

Majid, A., \& Burenhult, N. 2014. Odors are expressible in language, as long as you speak the right language. Cognition, 130(2), 266-270.

Marr, D., 1982. Vision: A Computational Investigation into the Human Representation and Processing of Visual Information. Freeman, San Francisco.

Mehrabian, A. and Russell, J.A., 1974. An approach to environmental psychology. Massachusetts: MIT Press.

Middleton, J., 2010. Sense and the city: exploring the embodied geographies of urban walking. Social and Cultural Geography, 11(6), 575-596.

McLean, K., 2012. Emotion, location and the senses: A virtual dérive smell map of Paris. In Proceedings of the 8th International Conference on Design and Emotion: Out of Control, pp. 11-14.

Naus, A., 1984. The occupational meaning of smell. Journal of Hygiene, Epidemiology, Microbiology, and Immunology, 29(1), 29-36.

Osborne, T. and Jones, P.I., 2017. Biosensing and geography: A mixed methods approach. Applied Geography, 87, 160-169.

Osgood, C. E., 1962. Studies on the generality of affective meaning systems. American Psychologist, 17(1), 10.

Porteous, J. D., 2006. Smellscape. In Drobnick, J. (ed.) The Smell Culture Reader.Berg Publishers, Oxford, pp. 89- 106. Original work was published in Progress in Human Geography, 9(3), 356-378.

Rose, Gillian. (2001). Visual Methodologies. Sage, London.

Rodaway, P., 1994. Sensuous geographies: body, sense and place. London: Routledge.

Riach, K. and Warren, S., 2015. Smell organization: Bodies and corporeal porosity in office work. Human Relations, 68(5), 789-809.

Schiffman, H. R., 1990. Sensation and Perception: An Integrated Approach. John Wiley \& Sons, New Jersey.

Śliwa, M. and Riach, K., 2012. Making scents of transition: Smellscapes and the everyday in 'old'and 'new'urban Poland. Urban Studies, 49(1), 23-41.

Smith, M., Davidson, J., Cameron, L. and Bondi, L., 2009. Emotion, Place and Culture. Routledge, London. 
Xiao, J., Tait, M. and Kang, J. (2020) Understanding smellscapes: sense-making of smell-triggered emotions in place. Emotion, Space and Society 37(2020) 100710. https://doi.org/10.1016/i.emospa.2020.100710

Spangenberg, E.R., Crowley, A.E. and Henderson, P.W., 1996. Improving the store environment: do olfactory cues affect evaluations and behaviors?. The Journal of Marketing, 67-80.

Synnott, A., 1991. Puzzling over the Senses: From Plato to Marx. In D. Howes (Ed.), The Varieties of Sensory Experience. A Source Book in the Anthropology of the Senses. University of Toronto Press, Toronto, pp. 71-76.

Tan, Q.H., 2013. Smell in the city: Smoking and olfactory politics. Urban Studies, 50(1), 5571.

Tolaas, S., 2010. The City from the perspective of the nose. Ecological urbanism. Baden: Lars Müller Publishers. 152-161.

Tuan, Y.F., 1977. Space and place: The perspective of experience. University of Minnesota Press, Minneapolis.

Thrift, N., 1996 Spatial Formations. Sage, London.

Thrift, N., 2004. Bare life. In Thomas, H. and Ahmed, J. (Eds.) Cultural Bodies: Ethnography and Theory. Blackwell Publishing Ltd, Oxford, pp. 145-169.

Trnka, S., 2012. When the world went color: Emotions, senses and spaces in contemporary accounts of the Czechoslovak Velvet Revolution. Emotion, Space and Society, 5(1), 45-51.

Twigger-Ross, C. L. and Uzzell, D. L., 1996. Place and identity processes. Journal of Environmental Psychology, 16, 205-220.

Tuan, Y. F., 1991. Language and the making of place: A narrative-descriptive approach. Annals of the Association of American Geographers, 81(4), 684-696.

Waskul, D.D. and Vannini, P., 2008. Smell, odor, and somatic work: Sense-making and sensory management. Social Psychology Quarterly, 71(1), 53-71.

Zardini, M. and Schivelbusch, W., 2005. Sense of the city: an alternate approach to urbanism. Lars muller publishers, Zürich. 